Paper submission to Studies in Conservation

\title{
New perspectives on the study of particulate matter deposition within historic interiors
}

\author{
J. Grau-Bové, M. Strlič, L. Mazzei, D. Thickett
}

\begin{abstract}
This paper proposes a new way of interpreting particulate matter deposition indoors. The rate of deposition of dust in surfaces is presented as the result of the combination two main factors: the concentration of suspended particles close to surfaces and their capacity to deposit, expressed as the deposition velocity. We suggest that either of these two factors can be altered in order to mitigate deposition. The implications of this perspective are explored using in-situ measurements in a historic property (Apsley House, London) and a computational fluid dynamics model of aerosol deposition. The cases studied involve the effect of outdoor wind on the ingress of particles, the consequences of leaving the main door open and the effects of the ventilation system on deposition. The results demonstrate that simulations can be used reliably to explore hypothetical scenarios or situations that would be experimentally challenging. The inputs and outputs of the computational model are discussed in view of its usability in preventive conservation.
\end{abstract}

Keywords: dust; particulate matter; PM2.5; monitoring; deposition; simulation; computational fluid dynamics

\section{Introduction}

The evidence suggests that deposition of particulate matter (PM) reduces the value of heritage surfaces. PM deposition can cause a loss of value by altering the aesthetic properties of surfaces (Brimblecombe \& Grossi, 2005), interacting chemically with the substrate (Grau-Bove, et al., 2015; Bartl, et al., 2015; Thickett, 2010) or inducing frequent cleaning (Sandwith, et al., 2006).

As a result, many heritage institutions are interested in PM monitoring. Particulates have been studied in all kinds of heritage environments: museums (Yoon \& Brimblecombe, 2001; Worobiec, et al., 2010; Camuffo, et al., 1999), historic buildings (Krupinska, et al., 2012; Ligocki, et al., 1993) and libraries (Andelova, et al., 2010), to cite some relevant examples. Monitoring methods and guidelines have been suggested by many institutions (Howell, et al., 2002). Research has also focused on establishing thresholds for acceptable deposition in terms of the minimum area coverage visible to visitors (Bellan, et al., 2000). Guideline deposition limits have been proposed in terms of area coverage as measured with a microscope. For example, Historic Royal Palaces aims to reduce deposition to 3\% monthly area coverage (Frame, 2013). This body of research has focused on particulate matter of any size, but with a clear preference for coarse dust. There is less interest for fine and ultrafine particles, which may be due to the difficulty of detection (Grau-Bove \& Strlic, 2013).

Monitoring PM in indoor heritage environments is necessary for risk assessment and source apportionment. Techniques such as thermography to detect gaps in the building envelope, or anemometer measurements to assess drafts, usually provide additional evidence to help interpretation. Monitoring alone is, however, often insufficient to inform preventive conservation. It is often difficult to establish the causes of deposition and, therefore, to use the data to enable mitigation strategies. We propose that mathematical models of deposition can provide further help to interpret deposition, generalise the conclusions and make predictions.

The existing simulation approaches have, however, some limitations: they are generally meant to describe wellmixed environments with simple box-like geometries. In our opinion, in order to enable preventive action, a model should (1) be able to estimate the deposition rates for different particle types and surface properties, (2) relate deposition to the inputs that can be controlled by heritage managers (temperature, ventilation, heating, position of objects, etc...) and (3) be applicable in any building geometry, from small rooms to large, multi-room environments.

In order to meet these needs, we have investigated the application of Computational Fluid Dynamics (CFD) in the simulation of deposition in indoor heritage environments. Many CFD models of PM deposition have been developed in the last decade, and they have been extensively used in indoor environments (Gao, et al., 2009; Hathway, et al., 2011; Lai \& Chen, 2006). Based on these previous investigations, we developed a CFD model that describes the dispersion and deposition of PM in indoor heritage environments (Grau-Bove, et al., 2015).

Here, the word "model" does not only refer to a set of equations and the methods to solve them. Our modelling efforts have been accompanied by the development of a conceptual framework that offers an interpretation of indoors deposition phenomena. We have validated the modelling approach in several case-study sites, which 
represent a wide range of building geometries and particle properties. In this paper, we use the description of experiments and simulations in one of these case studies as a vehicle to expose our new perspectives in particulate matter deposition.

\section{A theoretical framework for deposition}

This paper offers an interpretation of deposition phenomena in indoor heritage based on experimental observations and computer simulations. The mathematical model we use is described in detail elsewhere (GrauBove, et al., 2015), and here we will only concentrate on the conclusions that can be obtained using it. However, since the model plays no small role in shaping our theoretical framework, it is important to refer briefly to its main assumptions.

Deposition can be described mathematically in many ways. Fundamentally, when selecting a mathematical description, we are faced with a choice: do we describe each particle individually or do we describe particles as a continuous quantity that may present gradients? In heritage applications, the interest lies in the area-covering capacity of the particles, their concentration and their ingress fluxes indoors. All these are "bulk" properties of all the particles, and not properties of any individual particle. Consequently, we decided to simulate PM as a continuous phase.

Different types of models follow this approach: mass balance models with a few equations or fluid dynamics Eulerian models, which are more complex. But regardless of their complexity, these approaches have a common feature: when particles are suspended in air, they can be described with a concentration $(c)$, as if they were a gas. A gas, however, wit"h additional properties: it is affected by gravity depending on the diameter and mass of the particles, and it attaches to surfaces (i.e. surfaces are a sink of particles). The flow of the particles "through" the walls is described by the equation:

$J=v_{d} \cdot c($ Equation 1)

where $J$ is the particle flux (in mass or number of particles per unit area per unit time), $c$ is the mass or number particle concentration (in amount per volume) and $v_{d}$ is the particle deposition velocity. The deposition velocity is a crucial parameter: it describes the capacity of the particles to deposit in the system of interest. Its estimation is complex and still a matter of scientific enquiry. It depends on many parameters (particle size, temperature, turbulence, electrical charge, surface roughness), which are more or less important in different applications.

Equation 1 suggests a theoretical distinction in the causes of deposition. It shows that the deposition flux, which is the amount of particles that reach surfaces, is defined by two independent parameters: the concentration and the deposition velocity. We define, therefore, two different factors affecting the particle flux: (1) sources of particles and (2) drivers of deposition.

(1) A source of particles is anything that increases the value of $c$. E.g. A supply air vent, a fan, or a heating point that generates a convective flux.

(2) A driver of deposition is anything that increases the value of $v_{d}$. A cigarette, a candle, a leak in the wall with negligible velocity, can be sources of particles. Some phenomena, such an open window, can be both simultaneously.

\section{Site description and conservation issues}

The practical implications of this theory are best explained with a case study. In this paper we focus on Apsley House, an $18^{\text {th }}$ century historic house located in Hyde Park Corner, London, managed by English Heritage. This is one of the most polluted roundabouts in London, with an annual daily average vehicle flow of 55250 vehicles/day (Department for Transport, 2018) and annual $\mathrm{PM}_{10}$ concentrations close to $55 \mu \mathrm{g} / \mathrm{m}^{3}$, higher than the London average of approximately $30 \mu \mathrm{g} / \mathrm{m}^{3}$ (London Air, 2018). As a result the house experiences relatively high levels of PM deposition indoors, which leads to frequent cleaning of some surfaces. An important fraction of the observed deposition is composed of combustion particles that infiltrate from the outdoor environment. In previous research, we demonstrated that in Apsley House particles smaller than $2.5 \mu \mathrm{m}$ (often referred to as $\mathrm{PM}_{2.5}$ ) can be largely attributed to outdoor sources. Larger particles in this House are a consequence of the presence of visitors (Grau-Bove, et al., 2015). Figure 1 shows a schematic floor plan of the house, and some images are included in Figure 2.

The main gallery of the building (Waterloo gallery) has a HVAC system installed in 1995 by the Victoria and Albert Museum. Its supply and return inlets are indicated in Figure 2. A plant-room was built on the roof above the gallery. The plant draws external air from the roof, air underwent filtration and conditioning and was fed into the gallery by two ceiling vents (re-using original smoke ventilation in the ornate plaster ceiling). The air is 
extracted from the gallery through two separate existing vents in the gallery and recirculated overnight. It became clear in 2005 when English Heritage took over management of the site, that the system could not control the $\mathrm{RH}$ or temperature to anything near its specification of $50 \pm 5 \% \mathrm{RH}, 19-21^{\circ} \mathrm{C}$. Two large open doors to uncontrolled rooms and leaky windows and skylights, generated an infiltration rate that significantly exceeded the systems capacity. Data collected by English Heritage indicated a beneficial effect against the very high chemical pollution levels present outdoors. Chemical filtration and improved dust filtration were installed in 2007 (the level of dust filtration was limited by the plants original specification capacity). At the time of the measurements the humidifier had failed, but the plant was running on a filtration mode. As a result. during the experimental period the gallery also contained an additional humidifier which blew air vertically.

We investigated PM deposition in Apsley house in detail using measurements and simulations. Between January and September 2013, we collected a rich array of experimental data (deposition in several rooms, indoor and outdoor PM concentration, wind velocity and direction, thermal imaging of walls and windows), which we used to set-up and validate a computational fluid dynamics model of the building. Some monitoring locations are indicated in Figure 1. This research is described in detail elsewhere (Grau-Bove, et al., 2015) but, for clarity, we summarise here our main observations:

1. The indoor concentration of $\mathrm{PM}_{2.5}$ is dominated by wind direction, which defines the rate of infiltration through leaks in the building envelope (gaps in the windows and access doors).

2. Under typical wind conditions (South-West direction), the Indoor/Outdoor ratio of $\mathrm{PM}_{2.5}$ is $0.66 \pm 0.36$, which is reduced to $0.39 \pm 0.24$ when the wind is reversed (North-East direction).

3. Infiltration alone does not explain the measured monthly deposition. The simulations revealed that the operation of the ventilation system generates a certain pattern of deposition on the walls.

These conclusions have some implications for preventive conservation management. The third conclusion indicates that the ventilation system may have an effect on the spatial distribution of deposition. This raises questions of practical importance. Should its operation be limited? Given that most of the particles are of outdoor origin, it is important to determine the main infiltration points. The entrance to the building is the largest opening in the building envelope, and faces the predominant wind direction (South). Does it introduce many particles indoors? And how far do they penetrate into the building?

The computational model of Apsley House is well-suited to answer these questions. This model has already been validated experimentally, not only in Apsley House but also in a controlled laboratory setting (Grau-Bove, et al., 2016). In the following sections, we use the model in order to interpret PM behaviour in Apsley House in more detail, and to offer actionable evidence that can support the mitigation of deposition.

\section{Model set-up}

The CFD model is based on a 3D simulation of pollutant dispersion. It is an implementation of the transport equations suggested by Chen, et al. (2006) which describe deposition using the model developed by Lai and Nazaroff (2000). We also include infiltration through cracks following Liu and Nazaroff (2010). Our approach is described in detail elsewhere (Grau-Bove, et al., 2015, Grau-Bove, et al., 2016).

Leaving aside the numerical solution of the model, the inputs required to produce a simulation are few and easily obtained. All the necessary inputs are listed in Table 1. Firstly, a geometry needs to be defined. The level of detail is dependant of the desired output. For example, furniture is influential if we are simulating a single room, but may be less important in relation to the whole building. Figure 2 shows the computational representations used in this work, with different levels of detail.

Secondly, the relevant boundary information has to be introduced into the geometry. There are three types of boundary conditions: (1) "Wall" (where particles deposit), (2) "Inlet" (which introduces air, and optionally particles, into the system) and "Outlet" (through which air and particles leave the system). Each inlet requires the definition of an air velocity $(u)$. The air velocity in outlets, such as return air vents of HVAC systems, can be provided or calculated by closing the mass balance of air. In cases where temperature differences are important (e.g. underfloor heating), a temperature can be defined for each wall. Otherwise, walls can be considered isothermal.

The three types of boundary condition (Wall, Inlet and Outlet) can represent any indoor surface: underfloor heating can be a warm wall, a fan can be a round inlet of clean air and a window can be an inlet with a particle concentration equal to the outdoor concentration, etc. Finally, the properties of the particles (size and density) need to be specified. It would be possible to include other surface properties, such as roughness or electrical 
charge in the predictive models, but this would require further research. In particular, it is not known in which instances roughness and electrical charge have a significant impact on deposition.

Ideally, monitoring is needed in order to define the input variables. However, even without monitoring and scientific equipment, it is possible to obtain approximate values that can be the input of useful simulations. Outdoor concentration can be obtained using particle loggers. In absence of the required instrumentation, this information is sometimes available from publicly maintained monitoring stations. Simulations can still be carried out without knowledge of PM concentration. If we consider that the concentration outdoors is " 1 ", the output of the simulation will be in terms of Indoor/Outdoor $(\mathrm{I} / \mathrm{O})$ ratios instead than concentrations. In this paper, we use $c^{*}$ to refer to this non-dimensional concentration. The velocity in the supply air vents can be measured using anemometers. In their absence, it is possible to make reasonable assumptions on the direction and intensity of air flow, and still obtain insightful results.

To study deposition in Apsley House, we contemplate a simple case in which wind blows from the predominant south-west direction (Figure 3). As a result, air and particles enter the system through window leaks and the main door with the velocities summarised in Table 2 . The outputs of the model are the I/O ratio and the deposition rate to every surface. The values of $c$ and $v$ in each boundary are based on the estimations justified in Grau-Bove, et al., 2015.

\section{Sources of particles: infiltration}

The model can be used to study the importance of different particle sources. In the case of Apsley House, particles penetrate indoors through gaps and leaks in the building envelope, mainly in windows and around the main door. At the time of the experiment (January - June 2013) the gap under the main door was the largest single source of particles into the House. Measurements revealed a high concentration near the gap of $\sim 10.000$ particles $/ \mathrm{cm}^{-3}$ which decreased with distance from the door. Beyond the main hall, the I/O ratio approached the average and it was impossible to distinguish experimentally whether particles originated in this source or in a combination of sources elsewhere in the House.

Simulations can help to identify how influential a given source is. This can be useful in instances where experimental testing is not possible, or where it is necessary to compare different preventive conservation strategies. To demonstrate this concept, we investigated the influence of the main door gap in isolation by simulating the dynamic evolution of $c$ once the gap is open. In this simulation, $d_{p}=2.5 \square \mu \mathrm{m}, c^{*}$ inlet $_{1}=1$ (I/O, dimensionless), $\mathrm{u}_{\text {inlet }}=0.5 \mathrm{~m} / \mathrm{s}$.

Figure 4 shows the evolution of concentration simulated in two cases. Case A shows how the concentration in different rooms increases when the main door is left open. The higher air flow rate contributes to increased levels of transport of the particles. In this case a steady state in the main hall is reached approximately after $1 \mathrm{~h}$. However, at this time some particles are still travelling into the House without depositing. After $\sim 3 \mathrm{~h}$ we still detect an increase in $c$ in the dinning room, on the second floor.

Case B shows a scenario where the main door is closed. In this case, particles penetrate through the narrow gap under the door. After approximately $1 \mathrm{~h}$ a steady state is reached in the main hall. When the concentration ceases to evolve, the concentration in the rooms further away from the source is still very low (I/O $\sim 0.1)$. This implies that all the particles introduced into the House through the door gap deposit in the main hall and do not reach the upper floor. By closing this gap, one would significantly reduce deposition in the rooms close to the main hall. This simulation serves as an example of the potential of simulations to study different phenomena in isolation.

The previous simulation also demonstrates that the contribution of the main door to indoor levels of PM is limited to the immediately adjacent rooms (unless it is open for several hours, which is unlikely). Therefore, we can conclude that the fine particles present in other areas of the house are introduced through leaks, mainly located at the windows.

\section{Drivers of deposition: air movement}

We may now consider a second case: the operation of the ventilation system of the Waterloo gallery. Figure 5a and Figure 6 also show the concentration of particles when this ventilation system is switched on and off. The most visible result is the change in concentration in the Waterloo gallery. The cause could be that particles are displaced to other areas, or that positive air pressure in the Waterloo gallery prevents infiltration. The ventilation system has also an effect in the Portico room, but no visible effect on the Yellow room. These simulations seem to indicate that ventilation reduces the amount of dust in the room. However, concentration is just half the picture. These conclusions may change radically after a more detailed study of deposition velocities. 
We have seen that simulations can show the concentration of particles in each room of a building under different operation regimes. In this section we explore how these particles reach surfaces. A room without any air movement experiences between ten and a hundred times more deposition on the floor than on the vertical walls (Nazaroff, 1993). However, when air movement is significant, the deposition fluxes increase through different mechanisms:

- Turbulence increases the overall deposition. When air motion is turbulent, the differences in surface inclination become less important, and deposition on horizontal and vertical surfaces increases. The size of particles also becomes less influential, and the deposition rates may even become constant through a range of particle sizes.

- Near-wall flows create localized deposition. When air flows tangentially to a flat surface (generating a high wall shear stress), the deposition increases locally, often resulting in hotspots of deposition near supply air vent.

The simulations of deposition can be used to quantify these effects in Apsley House. The simulations that we provide here focus on the same cases solved previously: wind blows from the $\mathrm{S}-\mathrm{W}$, and the ventilation system is either on or off. Figure $5 \mathrm{~b}$ shows the calculated values of the deposition velocity $v_{d}$ in each room of Apsley House. These values are an average over all the vertical walls. Note that the homogeneity detected in the simulations of $c$ (outside the Waterloo Gallery) has vanished. Figure 5b shows marked differences of $v_{d}$ between rooms. Particularly, the simulations indicate that $\mathrm{v}_{\mathrm{d}}$ increases in the Waterloo Gallery when the ventilation system is in operation.

We studied deposition in the Waterloo Gallery room in greater detail by simulating it with a more accurate computational geometry (Figure 2c). Figure 7 shows the contours of deposition on the walls of the Waterloo gallery under different operation modes. The simulations of the Waterloo Gallery provided a good fit with the experimental data, as shown in Figure 8. The number codes of this figure refer to the sampling locations illustrated in the floor plan of the house (Figure 1).

Some of these sampling locations were placed vertically while some were horizontal and upward facing. Simulations predicted well the large differences between vertical and horizontal surfaces, but failed to predict subtler differences due to the position of the samplers. For example, it predicted the same deposition in locations $\mathrm{h} 1, \mathrm{~h} 2$, and h3, while in reality the measurements show a significant difference. This may be due to the choice of locations. Many of these samplers were located on top of painting frames, which have different shapes. In view of the results, it is likely that the shape of the painting frame, and the proximity of other frames, altered the air flow and affected locally the levels of deposition. In other words, the measurements are probably affected by factors other than the spatial distribution of the samplers. However, we can safely conclude that, in general, the model reflects the main trends of the data, and predicts well the order of magnitude of deposition.

The contour plots of deposition displayed in Figure 7 also offer some interesting insights. The simulations predict that the behaviour of PM in the room changes completely when the ventilation system is in operation. The contours of deposition velocity, $v_{d}$, in Figure 7a show that when the ventilation system is off deposition is prominent on the floor and reduced on vertical surfaces. Figure $7 \mathrm{~b}$ shows that the presence of the humidifier (labelled as D in Figure 2) increases slightly the deposition velocity on the neighbouring wall. When the ventilation is switched on (Figure 7c) in the Waterloo Gallery the gradients of $v_{d}$ change. Deposition becomes homogeneous, with increased levels of deposition on the walls. The air flow also induces higher deposition velocities on the areas close to the inlets and outlets.

\section{The interplay between concentration and deposition}

The analysis of the I/O ratios room by room (Figure 5a) and the deposition velocities (Figure 5b) brings us to an apparent contradiction: the ventilation system purges the Waterloo Gallery of particles, thus reducing the potential for deposition, but air motion increases the deposition velocity, thus increasing the ability of the particles to deposit. As a result, there is a trade-off between concentration mitigation and deposition mitigation. In this case, the combination of the two effects results in a slight reduction of the deposition flux $J$ (Figure $5 \mathrm{c}$ ). This case illustrates well the distinction between deposition velocity, concentration and deposition flux illustrated by Equation 1 .

The amount of particles that reaches surfaces (i.e. the particle flux, $J$ in Equation 1$)$ can be mitigated by reducing the amount of particles $(c)$ or by reducing their capacity to deposit $\left(v_{d}\right)$. Some environmental management actions can alter both parameters, and sometimes contradictorily. The action of a large ventilation system is a case in point: it has the capacity of improving ventilation and reducing concentrations, as well as to create turbulence and wall shear stresses that increase deposition. 
In such cases, a balance needs to be found. It is not, however, the role of this research to make a final recommendation in this instance, for several reasons. Firstly, the benefits of the ventilation system must be assessed in a broader framework including its use for climate control and its energy consumption, which would be outside the scope of this work. Secondly, we have carried out these illustrative simulations using only reasonable estimates of the ventilation rates, but precise measurements would be needed in order to quantify the flux of particles in every case. This would not change the principles discussed, but may change the cost-benefit relationships of the different management options.

\section{Emerging inhomogeneity}

The model we have described is a tool to predict the deposition velocity, $v_{d}$. In the previous sections we have discussed several contour plots based on this parameter, which has been very useful to visually express the variation of deposition in space. The main advantage of $v_{d}$ is that it illustrates neatly the relative importance of different drivers of deposition.

However, its magnitude is not easy to interpret. $v_{d}$ has units of velocity, typically $\mathrm{m} / \mathrm{s} \mathrm{or} \mathrm{cm} / \mathrm{h}$. It is not straightforward to relate $v_{d}$ to a physical process of which we have direct experience in our daily life. Looking at Figure $7 \mathrm{a}$, it is clear that some areas experience more deposition than others, but these contours can only be interpreted relative to each other. In order to obtain an actual estimation of the amount of dust on surfaces one should multiply the deposition velocity by a concentration, $c$, to obtain a flux, $J$ (Figure 9a).

But even $J$ is hard to use as actionable evidence. A possible solution is to convert the flux, $J$, into monthly area coverage. This of course requires not only the output of the model $\left(v_{d}\right)$, but also a reasonable estimate of $c$ for the period of interest and an understanding of the size distribution of the particles, or at least a representative diameter of the particles. To produce Figure $9 \mathrm{~b}$ we have used a particle size of $(2.5 \mu \mathrm{m})$ and a concentration of 100 particles $/ \mathrm{cm}^{3}$ chosen merely as an example. The profile of area coverage looks rather similar to the deposition flux, but now the units express a magnitude which is commonly monitored, and universally understood. Note that the results depend on the relative concentration of the different size modes. The more size bins used, the better the prediction of area coverage.

The percentages of area coverage expressed in Figure $9 \mathrm{~b}$ can be related to the daily practice of heritage institutions. But we can still go one step further and convert these values to a scale that is measured even more easily: the time required to reach visible coverage. This is achieved with the following equation:

\section{Time $=$ Target $/$ Flux $($ Equation 2)}

Where Time is the time until the target deposition is reached, Target is the deposition limit (in \%) and Flux is the deposition flux (expressed as \% per unit time). Figure 9c shows the time to reach 5\% area coverage which, as mentioned in the introduction, could be considered to be a typical threshold of unacceptable deposition. The values represented in Figure $9 \mathrm{c}$ can be directly related to the cleaning schedule of heritage institutions. This expression of the results requires an estimate of what can be considered "unacceptable deposition", which is unclear and a matter of current scientific discussion.

The expression of the results in terms of time to undesirable (or visible) area coverage (Figure 9c) reveals an evident inhomogeneity in the levels of deposition. While some areas such as the window sills become visibly dusty in days or weeks, others such as the upper corners of the walls, will only reach the same level of deposition after a year. By comparing this figure with the contours of concentration in the Waterloo gallery when the ventilation is off (Figure 6a) it becomes evident that "well-mixed" environments are compatible with inhomogeneous deposition. In the heritage field our interest lies in the surfaces, and not only in the free volume of air surrounding objects. Even when the concentration of particles in suspension does not display gradients, the deposition fluxes have many sources of inhomogeneity. The most evident one is surface properties: inclination and roughness. But, crucially, inhomogeneity also arises as a consequence of air flows, which depend on the relative position of inlets, outlets, and walls.

\section{Conclusions}

In this work, we have seen how CFD modelling of deposition in indoor heritage can help explore the complex relationships between infiltration, ventilation and room layout. The estimations of deposition fluxes and concentration are detailed enough to compare different scenarios and obtain actionable information. Often, this evidence cannot be obtained using any other method, or using other methods would be too costly. For example, the simulations revealed that the ingress of PM from the main door is limited to the surrounding rooms, and that it would reach the upper floors only after some hours. An experimental investigation of the same effect would have been not only impractical and an unnecessary risk (as this experiment would imply leaving the main door 
open for some hours). This would also technically challenging: it would require distinguishing between the infiltrated particles and the background concentration. We could reason similarly about other simulated cases, such as the different combinations of ventilation and wind direction. In that respect, simulations offer a cost effective, visual and fast method to explore speculative scenarios and compare different management options.

The contribution of our modelling approach is not, however, merely technical. We believe that a model offers not only a mathematical description of certain phenomena, but also a conceptual framework to interpret it. The development of the model gives rise to new concepts that can be used to understand experimental evidence. We have seen that deposition events can be described in terms of "sources of particles" (i.e. something that increases c) and "drivers of deposition" (i.e. something that increases $v_{d}$ ). This distinction allows us to classify and understand a range of indoor phenomena. In our case, the main sources of particles studied were leaks in the window frames and the main door. The main drivers of deposition were gravity and air movement. For example, the dehumidifer increased deposition on the neighbouring wall. In some cases, there might be events that are a both a source of particles and driver of deposition. This could be, for example, an open window or a walking visitor. These simultaneously increase dust levels and induce air movement that leads the dust to surfaces.

Finally, we have shown that the model requires relatively few inputs, which are for the most part easily accessible. Naturally, the model predictions will be only as good as the input data. Depending on the quality of the input, this modelling approach can provide very precise or very vague estimations, which we see as a strength rather than a limitation. It implies, in our view, that even with approximate inputs it is possible to explore the consequences, synergies and unintended effects of mitigation actions. The ubiquity of environmental sensors in historic buildings offers a valuable potential resource for model validation and fine-tuning. It may be that there is still a long way to go before such simulations can be carried out outside an academic research setting. The evidence is, however, promising: our simulations have been carried out in a regular laptop, and every day new developments in fluid dynamics codes make their use more user-friendly and less costly. As has happened with CAD, 3D modelling, or photogrammetry, CFD simulations could become a household name in preventive conservation.

\section{References}

Andelova, L. et al., 2010. Characterization of airborne particles in the Baroque Hall of the. E-Preservation Science, Volume 7, pp. 141-146.

Bartl, B. et al., 2015. The effect of dust particles on cellulose degradation. Studies in Conservation.

Bellan, L. M., Salmon, L. G. \& Cass, G. R., 2000. A Study on the human ability to detect soot deposition onto works. Environmental Science \& Technology, 34(10), pp. 1946-1952.

Brimblecombe, P. \& Grossi, C. M., 2005. Aesthetic thresholds and blackening of stone buildings. The Science of the Total Environment, 349(1-3), pp. 175-89.

Camuffo, D. et al., 1999. Indoor air quality at the Correr Museum, Venice, Italy. The Science of the Total Environment, 236(1-3), pp. 135-52.

Chen, F., Yu, S. \& Lai, A., 2006. Modeling particle distribution and deposition in indoor environments with a new drift-flux model. Atmospheric Environment, 40(2), pp. 357-367.

Crump, J. G. \& Seinfeld, J. H., 1981. Turbulent deposition and gravitational sedimentation of an aerosol in a vessel of arbitrary shape. Journal of Aerosol Science, 12(5), pp. 405-415.

Department for Transport, Traffic Counts website (url: https://www.dft.gov.uk/traffic-counts/about.php). Last visted: May 2018.

Foarde, K. K., VanOsdell, D. W. \& Chang, J. C. S., 1996. Evaluation of Fungal Growth on Fiberglass Duct Materials for Various Moisture, Soil, Use, and Temperature Conditions. Indoor Air, 6(2), pp. 83-92.

Frame, K., 2013. Creative conservation risk management: evolving a collection risk management strategy at a major heritage attraction.. Collections, 9(1), pp. 103-114.

Gao, N., Niu, J., Perino, M. \& Heiselberg, P., 2009. The airborne transmission of infection between flats in high-rise residential buildings: Particle simulation. Building and Environment, 44(2), pp. 402-410. 
Grau-Bove, J. et al., 2016. The effect of particulate matter on paper degradation. Heritage Science - Submitted, 4(2), 1-8.

Grau-Bove, J., Mazzei, L., Strlic, M. \& ., 2016. Applicability of a drift-flux model of aerosol deposition in a test tunnel and an indoor heritage environment.. London, UK, s.n., pp. 106 (2016): 78-90.

Grau-Bove, J. et al., 2014. CFD simulation of aerosol deposition in Apsley House, London. London, UK, s.n.

Grau-Bove, J. et al., 2015. Simulation of particulate matter ingress, dispersion and deposition in a historical building. Journal of Cultural Heritage.

Grau-Bove, J. \& Strlic, M., 2013. Fine particulate matter in indoor cultural heritage: a literature review. Heritage Science, 1(1), p. 8.

Harving, H. et al., 1991. House dust mite allergy and anti-mite measures in the indoor environment. Allergy, Volume 46, pp. 33-38.

Hathway, E., Noakes, C., Sleigh, P. \& Fletcher, L., 2011. CFD simulation of airborne pathogen transport due to human activities. Building and Environment, 46(12), pp. 2500-2511.

Howell, D., Brimblecombe, P., Lloyd, H. \& Knight, B., 2002. Monitoring dust in historic houses. In: Proceedings of Conservation Science. London: Archetype Publications.

K. Lai, A. C. \& Nazaroff, W. W., 2000. Modeling indoor particle deposition from turbulent flow onto smooth surfaces. Journal of Aerosol Science, 31(4), pp. 463-476.

Krupinska, B. et al., 2012. Assessment of the air quality (NO2, SO2, O3 and particulate matter) in the PlantinMoretus Museum/Print Room in Antwerp, Belgium, in different seasons of the year. Microchemical Journal, 102(0), pp. 49-53.

Lai, A. C. \& Chen, F., 2006. Modeling particle deposition and distribution in a chamber with a two-equation Reynolds-averaged Navier-Stokes model. Journal of Aerosol Science, 37(12), pp. 1770-1780.

Lefèvre, R. \& Sabbioni, C., 2010. Climate change and cultural heritage. Ed.Edipuglia.

Lehtovuori, P., 2007. Economics and Built Heritage: Seminar Proceedings : Built Heritage--value Adding Sector. s.l.:Nordic Council of Ministers.

Ligocki, M. P. et al., 1993. Characteristics of airborne particles inside southern California. Atmospheric Environment, 27(5), pp. 697-711.

Liu, D.-L. \& Nazaroff, W. W., 2010. Particle penetration through building cracks. Aerosol Science and Technology, 37, pp. 37-41.

London Air website (url: http://www.londonair.org.uk/). Last visted: May 2018.

Nazaroff, W., 1993. Airborne particles in museums. Getty Conservation Institute, Marina del Rey, California.

Nazaroff, W. \& Cass, G., 1991. Protecting museum collections from soiling due to the deposition. Atmospheric Environment. Part A. General Topics, 25(5-6), pp. 841-852.

Sandwith, H., Stainton, S. \& Cornforth, J., 2006. The National Trust manual of housekeeping: the care of collections. s.l.:National Trust, Elsevier.

Thickett, D., 2010. Micro-Spectroscopy: a powerful tool to understand deterioration. e-Preservation Science, pp. 158-164.

Worobiec, A. et al., 2010. Transport and deposition of airborne pollutants in exhibition areas. Journal of Cultural Heritage, 11(3), pp. 354-359.

Yoon, Y. H. \& Brimblecombe, P., 2001. The distribution of soiling by coarse particulate matter in the museum environment. Indoor air, 11(4), pp. 232-40. 


\section{Figure captions}

1. Plan of Apsley House. The main entrance is located in (A). Two rooms are equipped with environmental equipment that can displace air: the Plate and China room, with two electrical heaters (B) and the Waterloo Gallery (C), equipped with a ventilation system in the ceiling and a dehumidifier (D). The labels h1, h2, h3, h4 and h5 refer to horizontally placed particulate matter samplers, and v1, $\mathrm{v} 2$, v3 and $\mathrm{v} 4$ to vertically placed samples.

2. Computational representations of the simulated environments with different levels of detail, including the building envelope (a), the interior volumes (b) and a more refined model of the Waterloo Gallery (c). (A) Indicates the location of the main entrance, (B) the electrical heaters and (C) supply air vents and return air vents of the Waterloo Gallery HVAC system (D) location of the dehumidifier. Image (d) shows the building in context, obtained from imagery from Google Map data @2015. Images (e) and (f) show the house and the interior of the Waterloo Gallery.

3. Average wind rose for the experimental period, showing the recorded wind speed in each direction (January to September 2013).

4. Evolution of concentration at different rooms of Apsley House if the main door is fully open (main door open) or air penetrates through the gap under the door (Only infiltration).

5. Simulated values of $c^{*}$ (non-dimensional concentration or I/O ratio), $v_{d}$ (deposition velocity) and $J$ (deposition flux) in several rooms. Wind is South-West and the Waterloo Gallery ventilation system is on and off. Particle diameter $=2.5 \mu \mathrm{m}$. Boundary conditions as described in Table 2 .

6. Simulated concentration profiles of $c^{*}$ (non-dimensional concentration or I/O ratio) on the whole interior volume of the Apsley House under South-West wind and the Waterloo Gallery ventilation on and off. Particle diameter $=2.5 \mu \mathrm{m}$. Boundary conditions as described in Table 2 .

7. Simulated contours of deposition in the Waterloo Gallery under different modes of operation: only infiltration (a), infiltration and humidifier (labeled "D")in operation (b) and infiltration with ventilation in operation (c).

1. Comparison between experimental results and simulations. The box-plots represent the distribution of values related to the changes in environmental concentration during the experimental period (the box illustrates the average and the first and third quartile, and the whiskers the maximum and minimum values).

2. Contours of deposition in the Waterloo gallery (results from Figure 7a, without mechanical ventilation) using different types of graphical representation: deposition flux (a), the area coverage (b) and the time required to reach visible (5\%) area coverage (c). 
$\underline{\text { Table Captions }}$

1. Summary of required input parameters for a CFD simulation of dust deposition.

2. Values of the input parameters used in the reported simulations. 
Table 1

\begin{tabular}{|l|l|l|l|}
\hline \multirow{2}{*}{ Geometry } & Variable & Input information & $\begin{array}{l}\text { Instrumentation } \\
\text { needed }\end{array}$ \\
\hline & $x, y, z$ & $\begin{array}{l}\text { Dimensions of the room(s) } \\
\text { Position of the furniture } \\
\text { Location of inlets and outlets }\end{array}$ & \\
\hline $\begin{array}{l}\text { Inlet } \\
\text { boundaries }\end{array}$ & $u_{i}$ & Adentity of each boundary (inlet, outlet or wall). & \\
\hline $\begin{array}{l}\text { Outlet } \\
\text { boundaries }\end{array}$ & $c_{i}$ & $\begin{array}{l}\text { Particle concentration (if unknown, the I/O ratio can } \\
\text { be simulated instead) }\end{array}$ & Particle counter \\
\hline $\begin{array}{l}\text { Wall } \\
\text { boundaries }\end{array}$ & $T_{i}$ & In general, no information needed ${ }^{1}$ & \\
\hline $\begin{array}{l}\text { Particle } \\
\text { properties }\end{array}$ & $d_{p}$ & Pemperature, if higher than ambient & $\begin{array}{l}\text { Thermometer or } \\
\text { thermal camera }\end{array}$ \\
\hline & $\rho$ & Particle density (approximate & $\begin{array}{l}\text { Particle counter or } \\
\text { microscope }\end{array}$ \\
\hline
\end{tabular}

${ }^{1}$ No further definition is needed for "passive" outlets. However, ventilation or air cleaning devices with a set intake rate may be defined with a velocity or a flux.

$2 \rho$ has a limited impact on the results when air motion is relevant, which is when the model is applicable. In absence of better estimates, it is common practice to choose a value between $1.5 \mathrm{~g} / \mathrm{cm}^{3}$ (the density of limestone) and $2 \mathrm{~g} / \mathrm{cm}^{3}$ (the density of glass). 
Table 2

\begin{tabular}{|c|c|}
\hline Boundary & Input \\
\hline Main door & $\begin{array}{l}\text { If open, it is an inlet with } u=1 \mathrm{~m} / \mathrm{s}^{1}, c^{*}=1 \text {. } \\
\text { If closed, it is a wall. }\end{array}$ \\
\hline $\begin{array}{l}\text { Window leaks (South } \\
\text { and West façades) }\end{array}$ & Inlets, with $u=0.01^{2} \mathrm{~m} / \mathrm{s}, c^{*}=1$ \\
\hline $\begin{array}{l}\text { Window leaks } \\
\text { (North and East } \\
\text { façades) }\end{array}$ & Outlets, with $c^{*}=0$. \\
\hline $\begin{array}{l}\text { Waterloo ventilation } \\
\text { inlets }\end{array}$ & $\begin{array}{l}\text { If on, they are inlets of clean air, with } u=0.5^{2}, c^{*}= \\
0.1 \text {. If off, they are walls. }\end{array}$ \\
\hline Waterloo dehumidifier & The dehumidifier inlet has with $u=0.1^{1} \mathrm{~m} / \mathrm{s}$. \\
\hline $\begin{array}{l}\text { Waterloo ventilation } \\
\text { outlets }\end{array}$ & Always outlets, with $c=0$. \\
\hline $\begin{array}{l}\text { Floor, ceiling, walls, } \\
\text { furniture. }\end{array}$ & Isothermal walls. \\
\hline
\end{tabular}

${ }^{1}$ Measurements obtained with an anemometer, rounded-up.

${ }^{2}$ Estimation based on previous simulations Grau-Bove, et al., 2015. 